Paul E. Sijens

\title{
Parametric exploration of the liver by magnetic resonance methods
}

Received: 4 February 2009

Revised: 24 April 2009

Accepted: 30 April 2009

Published online: 6 June 2009

(C) The Author(s) 2009.

This article is published with open access at Springerlink.com
P. E. Sijens $(\bowtie)$

Radiology, University Medical Center Groningen and University of Groningen, Hanzeplein 1,

9713 GZ Groningen, The Netherlands e-mail: p.e.sijens@rad.umcg.nl

Tel.: +31-50-3613534

Fax: $+31-50-3611798$
Abstract MRI, as a completely noninvasive technique, can provide quantitative assessment of perfusion, diffusion, viscoelasticity and metabolism, yielding diverse information about liver function. Furthermore, pathological accumulations of iron and lipids can be quantified. Perfusion MRI with various contrast agents is commonly used for the detection and characterization of focal liver disease and the quantification of blood flow parameters. An extended new application is the evaluation of the therapeutic effect of antiangiogenic drugs on liver tumours. Novel, but already widespread, is a histologically validated relaxometry method using five gradient echo sequences for quantifying liver iron content elevation, a measure of inflammation, liver disease and cancer. Because of the high perfusion fraction in the liver, the apparent diffusion coefficients strongly depend on the gradient factors used in diffusion-weighted MRI. While complicating analysis, this offers the opportunity to study perfusion without contrast injection. Another novel method, MR elastography, has already been established as the only technique able to stage fibrosis or diagnose mild disease. Liver fat content is accurately determined with multivoxel MR spectroscopy (MRS) or by faster MRI methods that are, despite their widespread use, prone to systematic error. Focal liver disease characterisation will be of great benefit once multivoxel methods with fat suppression are implemented in proton MRS, in particular on high-field MR systems providing gains in signalto-noise ratio and spectral resolution.

Keywords Magnetic resonance imaging - Quantification · Liver

\section{Introduction}

Although hepatic MR is now widely performed, it is still mainly used to detect focal lesions. However it is becoming much more widely appreciated that MR can provide a wide range of information about hepatic function and clinicians are beginning to request such investigations. Hence a review article is considered timely in order to familiarise more general radiologists about what MR can now offer.

\section{Perfusion}

The liver is supplied with blood by the portal vein (75\%) and by the hepatic artery (25\%). Hepatic perfusion disorder refers to perfusion differences among segments, subsegments and lobes of the liver caused by various aetiologies, such as portal vein obstruction, liver cirrhosis, hepatic neoplasms, hepatic trauma, hereditary haemorrhagic telangiectasia, hepatic vein obstruction, steal phenomenon by 
hypervascular tumours, inflammatory changes, aberrant blood supply and hepatic parenchymal compression $[1,2]$. MRI contrast agents are intended to improve lesion detection and characterisation by increasing liver-lesion contrast. These agents include nonspecific extracellular gadolinium (Gd) chelates, reticuloendothelial systemspecific (RES) iron oxides and hepatocyte-selective agents [3]. All contrast agents used in MRI of the liver display their effect by decreasing $\mathrm{T} 1$ relaxation times $(\mathrm{Gd}$ and manganese $[\mathrm{Mn}]$ ) and $\mathrm{T} 2$ relaxation times of liver parenchyma (superparamagnetic iron oxides). After extracellular contrast agent has been injected, the liver is imaged in the hepatic artery (18-20 s delay), portal vein (45-60 s) and interstitial (1.5-5 $\mathrm{min})$ phases, and it can be characterised by the enhancement pattern during these phases and the differences between the degree and duration of enhancement and washout [3]. During the hepatic arterial dominant phase haemangiomas, metastases and hepatocellular carcinomas show heterogeneous enhancement, while adenomas and focal nodular hyperplasia are enhanced uniformly. In the portal vein phase the liver signals are very intense, whereas the other structures show delayed enhancement and washout phenomena. Reticuloendothelial systemspecific contrast agents contain iron oxide particles and they affect RES cells, receptors in cell walls or the blood pool, leading to signal loss in normal liver parenchyma as observed in $\mathrm{T} 2 *_{-}$and $\mathrm{T} 2$-weighted sequences. RESspecific contrast is frequently used in MR angiography. Hepatocyte-selective, Mn-containing contrast agents, taken up by hepatocytes and eliminated through bile, reveal nonenhancing lesions such as haemangiomas, metastases, cholangiocarcinomas and lymphomas.

Up to now quantitative perfusion MRI studies of the liver have mainly focused on tissue characterisation with Gd contrast, using the hepatic perfusion index (HPI), mean transit time (MTT), distribution volume (DV), total blood flow $(\mathrm{Ft})$, arterial blood flow $(\mathrm{Fa})$ and portal blood flow $(\mathrm{Fp})$ as parameters. It was reported that the values of Ft, Fa, Fp and DV are significantly higher in hepatocellular carcinoma than in liver metastases of colorectal cancer, whereas MTT is higher in the metastases [4]. The largest and most significant difference between hepatocellular carcinoma and colorectal metastatic cancer was that in $\mathrm{Fp}$ : 8.1 vs. $0.03 \mathrm{~mL} / \mathrm{min} / \mathrm{g}$ (median values; $p=0.0001$ ). The example in Fig. 1 illustrates that in hepatocellular carcinoma and in colorectal metastases total blood flow is, respectively, higher and lower than in normal liver tissue [4]. In hepatic metastases the HPI, initially elevated compared with the whole liver $(0.75 \pm 14$ vs. $0.66 \pm 0.16$; $p<0.01)$, was shown to decrease by $15 \%(P<0.05)$ after treatment with an antiangiogenic compound [5]. This opens up the therapeutic monitoring of antiangiogenic drugs in liver tumours as a promising new application of perfusion-weighted MRI. In patients with advanced liver fibrosis Fa and MTT were about three times as large as in controls ( $p<0.01$, in both cases) [6]. It is concluded that the

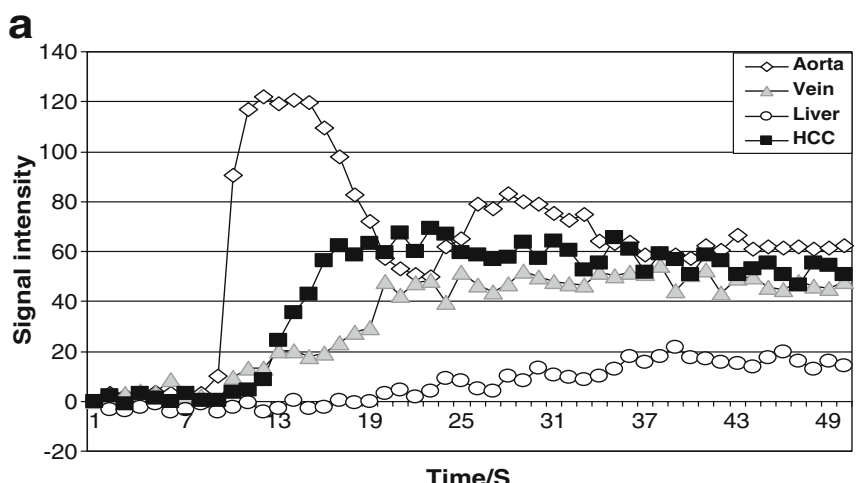

b

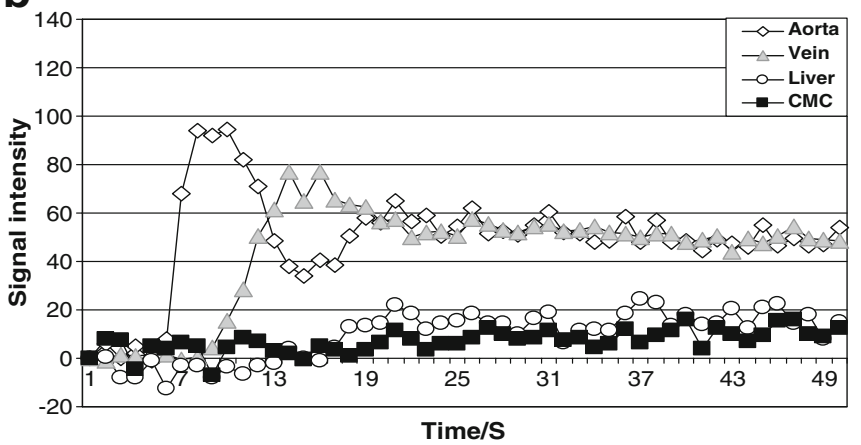

Fig. 1 Signal intensity vs. time curves of the liver, aorta, portal vein and nodule $\mathbf{a}$ in a man with hepatocellular carcinoma (the total blood flow is higher in the hypervascular tumour than in the liver parenchyma) and $\mathbf{b}$ in a woman with colorectal metastatic cancer (the total blood flow is lower in the hypovascular metastasis than in normal liver) (reproduced with permission from Abdullah et al. [4])

use of contrast-enhanced MRI for the noninvasive diagnosis of hepatocellular carcinoma can make an important contribution to patient prognosis, and in the identification and characterisation of liver lesions such as distinguishing between malignant and benign lesions. Although, currently, combined use of contrast-enhanced spiral CT in arterial phase and portal phase is considered the most sensitive imaging technique [2] and contrast-enhanced ultrasonography also remains a good alternative to contrast-enhanced MRI [7], MRI with specific contrast enhancement may offer more relevant information on hepatic perfusion abnormalities.

\section{Iron content}

Ferritin concentration in plasma reflects the amount of ferritin, the iron storage molecule in the human body, within body cells and has thus been used for decades as a diagnostic indicator of the iron concentration in the liver [8]. This measure of the size of iron stores in the liver is a key parameter in the management of haemochromatosis and other diseases associated with iron overload and an important cofactor in the morbidity attributed to many 
disorders including cancer and cardiovascular diseases. The most common cause of an elevated plasma ferritin level other than an increase in iron stores per se is inflammation. In inflammation, liver disease, cancer and some other diseases, the serum ferritin concentration is increased disproportionally to stores, suggesting an additional effect of ferritin turnover [9-11].

Iron behaves like a contrast agent with a $\mathrm{T} 2 *$ effect. Under these conditions the concentration is proportional to $\mathrm{R} 2 *(=1 / \mathrm{T} 2 *)$. In determining iron stores, MRI can replace invasive liver biopsy, and is less influenced by coexisting conditions than is the case with serum ferritin [12]. Different MRI protocols are available based on the measurement of signal intensity ratios and relaxometry techniques [13-15]. In particular, gradient-recalled echo (GRE) sequences are accurate for the estimation of hepatic iron concentration [16]. Obviously, in these MRI examinations pre-"contrast" series are not available, so the results in patients must be compared with those in other patients and healthy controls. Recently, an analysis method aimed at making the results independent of the quality of the shim and interindividual variations was validated by biopsy in 149 patients [17]. Gandon et al. used a set of five gradient echo sequences for determining the signal intensity values in regions of interest located within liver and (reference) muscle tissue to determine liver/muscle signal ratios. An algorithm yields hepatic iron concentration by selecting the most accurate outcome from the receiver operating characteristic curve of each sequence [17]. This method applied in 28 patients showed significant correlation with blood plasma ferritin content (Spearman's $r=0.66 ; P<0.001$ ) and a slightly improved correlation coefficient when limited to those patients known to not have inflammation $(r=0.82$; $n=17 ; P<0.001)[18]$. Concerning haematological disease, there was correlation between liver iron content and plasma ferritin level $(r=0.79 ; n=13 ; P=0.001)$. It was concluded that in patients without inflammation and in patients with haematological disease the content of ferritin in blood is a better predictor of liver iron content than in other patient categories [18]. One should be aware that serum ferritin levels can be confounded by factors such as infection, inflammation and malignancy, resulting in inaccurate reflections of tissue iron concentration. In the literature, correlations of MRI measures of liver iron content and plasma ferritin concentration are scarcely documented. In recent studies of thalassaemia patients, serum ferritin levels were shown to correlate significantly with liver T2 values, $\mathrm{T} 2 *$ values and/or with the liver-to-muscle signal ratios $[19,20]$. An example showing a significant inverse correlation between $\mathrm{T} 2 *$ and serum ferritin is shown in Fig. 2. Alústiza et al. [21] compared the method of Gandon with the results of biopsies, and the results indicated a positive argument for the reproducibility of Gandon's technique. Several other authors also use Gandon's method, for example, as inclusion criteria in a trial [22] or in a study in patients with beta-thalassaemia [23].

At this time, the method of Gandon et al. [17] appears to be the most suitable technique for the noninvasive measurement of liver iron concentration in view of the important histological correlations. Compared with an earlier biopsy-validated method [13], inter- and intraobserver correlations are better [24]. The enhanced accuracy is probably the result of the automated preselection of one of the five most sensitive sequences in the estimated liver iron concentration range. Correlation with serum ferritin depends on inflammation/infection parameters and on underlying disease, reflecting the more reliable measurement of body iron stores by MRI compared with serum ferritin. The question is raised whether MRI protocols to measure liver iron concentration can be applied to MR systems other than that on which they are validated. The reproducibility observed by Alústiza et al. [21] reinforces the possibility of using this method on any 1.5-T MR system. A limitation in Gandon's method is that signal measurements must be performed with the body coil, because when using smaller coils (such as the phased-array coil) for signal reception the reference signal intensities in muscle signal are unreliable. The requirement of good $B_{0}$ and $B_{1}$ field homogeneity over the entire field of view and field-dependent changes in relaxation behaviour should be
Fig. 2 Relationship between liver $\mathrm{T} 2 *$ values and serum ferritin concentrations in the entire study population. Dashed lines represent the reference range for liver $\mathrm{T} 2 *$ values and an arbitrary limit of $2,000 \mu \mathrm{g} / \mathrm{L}$ for serum ferritin $(n=64$; $r=0.465 ; P<0.011$ ) (reproduced with permission from Perifanis et al. [19])

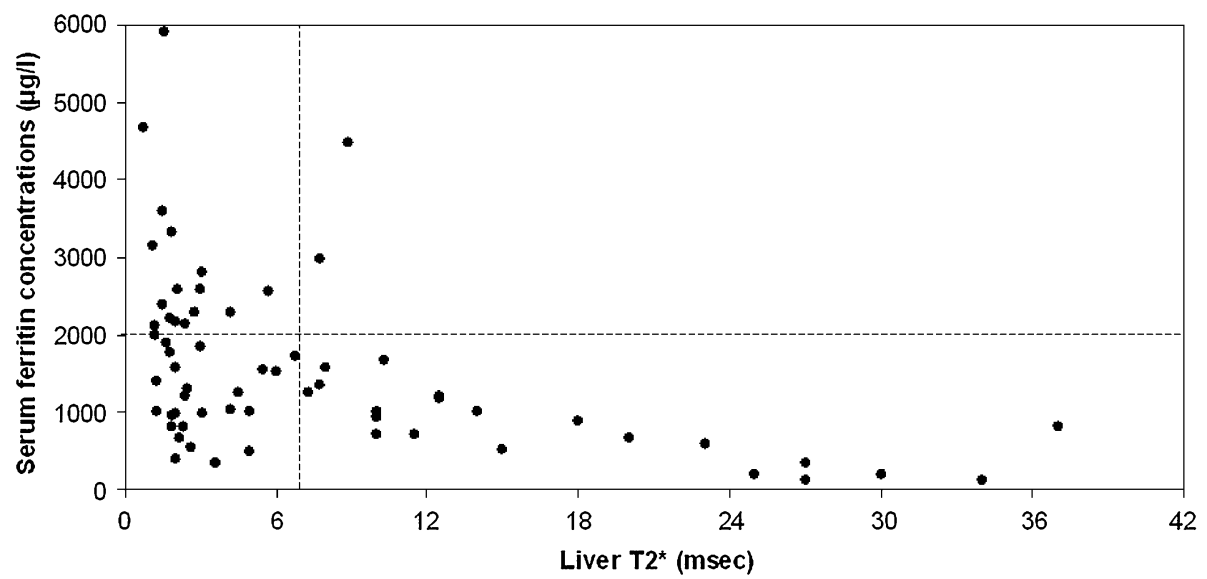


taken into account when adapting Gandon's method on MR systems of $3 \mathrm{~T}$ and up. All factors that influence $\mathrm{T} 2 *$ (quality of the shim, inflammation, fibrosis, steatosis, etc.) will affect the quality of the measure and must be taken into account when interpreting the results.

In iron overload studies, more than $70 \%$ of body iron is found in the liver and liver iron content has been considered the best marker of total body iron burden [15]. However, hepatic iron deposition measured by MRI and serum ferritin has shown little correlation with the iron levels in other organs, such as the pituitary gland or the heart $[15,19]$. Important decisions in, for example, the clinical management related to cardiac risk, should therefore not rely on these parameters [19].

\section{Diffusion}

In the last decade, measurement of apparent diffusion coefficient (ADC) of the water molecules through tissues has developed into another useful tool in the characterisation of hepatic lesions and in the evaluation of diffuse liver disease. This MRI application has no equivalent in other diagnostic techniques. The principle is that in the presence of magnetic field gradients, displacement of spins during the echo time of a spin-echo sequence produces a phase shift of the transverse magnetisation. This loss of phase coherence in the transverse magnetisation causes a spinecho amplitude attenuation in addition to that created by the spin-spin relaxation process [25]:

$$
\mathrm{S}(\mathrm{TE})=\mathrm{S}(0) \cdot \mathrm{B} \cdot \exp (-\mathrm{TE} / \mathrm{T} 2)
$$

in which $B$ is equal to $\exp (-b \cdot D)$, with $b$ a gradient factor depending on the gradient pulse sequence and $D$ the diffusion coefficient. Diffusion-weighted imaging (DWI) was initially used for the qualitative assessment of the impact of a gradient applied for a certain time per area unit on echo planar MR images. Right now, series measured with two or more gradient factors are in use to be able to quantify ADC, for example $b=0 \mathrm{~s} / \mathrm{mm}^{2}$ and $b=1,000 \mathrm{~s} / \mathrm{mm}^{2}$ (measured with the same TE in order to eliminate the T2 term). In this case the ADC or the degree of molecular motion of water measured on DWI is calculated as follows:

$$
A D C_{b 0, b 1}=\frac{-1}{b 1-b 0} \ln \left(\frac{I_{b 1}}{I_{b 0}}\right)
$$

where $I_{b 1}$ and $I_{b 0}$ are the DW intensities measured using a high and low $b$ value, respectively (for instance 0 and $1,000 \mathrm{~s} / \mathrm{mm}^{2}$ ). Studies on various organs in the human body have shown that measured ADC values depend on the gradient factors chosen, as at the lower end of the range $\left(b 1<400 \mathrm{~s} / \mathrm{mm}^{2}\right)$ microcirculation or perfusion tends to increase the overall $\mathrm{ADC}$ value measured, whereas at $b 1>400 \mathrm{~s} / \mathrm{mm}^{2}$ increased contributions from restricted and compartmentalised cellular environments tend to decrease ADC [25-27]. As a matter of fact, it has been shown that in the liver diffusion is not monoexponential $[25,28]$. A recent DWI study using ten $b$ factors running from 0 to $800 \mathrm{~s} / \mathrm{mm}^{2}$ indicated that the perfusion component is about $30 \%$, meaning that, unlike in the brain, the effects of perfusion are far from negligible in the liver [28]. This has enhanced the discrepancies between liver DWI studies from institutions using different $b$ value sets, but also offers opportunities to study liver perfusion without the need for contrast injection. At this time, the latter prospect remains theoretical without any routine application in liver MRI up to now. The optimum $b$ factors for the best contrast in imaging are related to TE, the signal-to-noise ratio of the sequence, the T2 and diffusion components of the studied structures.

In one clinical study, in which the $b$ values were optimised for the detection and characterisation of benign and malignant hepatic lesions, the specificities were similar for all sequences [29]. However, the sensitivity for malignant lesions turned out to be highest for $b 1=100 \mathrm{~s} / \mathrm{mm}^{2}$, whereas that for benign lesions was best for $b 1=800 \mathrm{~s} / \mathrm{mm}^{2}$ [29]. At $b 1$ values of 100 and, to a lesser extent, $200 \mathrm{~s} / \mathrm{mm}^{2}$ the ADC values in hepatocellular carcinomas, metastases and haemangiomas were elevated by perfusion contributions. This compares with demonstrations that in normal liver and in hepatocellular carcinoma at $b=150 \mathrm{~s} / \mathrm{mm}^{2}$ the contribution to the capillary flow to the signal attenuation is eliminated $[30,31]$ and that the mean perfusion fractions in liver, hepatocellular carcinoma, metastasis and haemangioma are $0.29,0.15,0.22$ and 0.35 , respectively [30]. In another study, however, the ADC values in hepatocellular carcinoma, hepatic metastases, cavernous haemangioma and hepatic cyst were found to be unaffected at $b 1$ values of 100,500 and $1,000 \mathrm{~s} / \mathrm{mm}^{2}$, with decreasing spread of values at increasing $b 1$, indicating that the calculated $\mathrm{ADC}$ values would be most accurate at the highest $b 1$ value used [32]. The ADC of hepatocellular carcinoma is slightly lower than ADC in normal liver tissue, that of hepatic metastases was slightly higher and the ADCs of cavernous haemangioma and hepatic cyst exceed the ADC of liver clearly [32,33]. Here, it is noted that whereas the diffusion properties of simple cysts approximate those of free water, the ADC values of hydatid hepatic cysts, containing structures such as a visible cyst wall, multivesicular appearance, floating membranes or calcification, tend to be slightly lower [34]. The closeness of the ADC values of malignant lesions (hepatocellular carcinoma, hepatic metastases) to those of normal liver underlines that the choice of $b$ values is crucial in the detection of liver tumours by DWI. This is illustrated by Fig. 3. The ADC value of cirrhotic liver tissue is lower than that of normal liver and the ADC of liver in patients with haemosiderosis is very low [33]. Using $b$ values up to $400 \mathrm{~s} / \mathrm{mm}^{2}$, higher liver and cirrhotic liver ADC values were obtained than with $b$ values of up to $800 \mathrm{~s} / \mathrm{mm}^{2}$, whereas the significance of the difference between liver and cirrhotic liver was highest at 

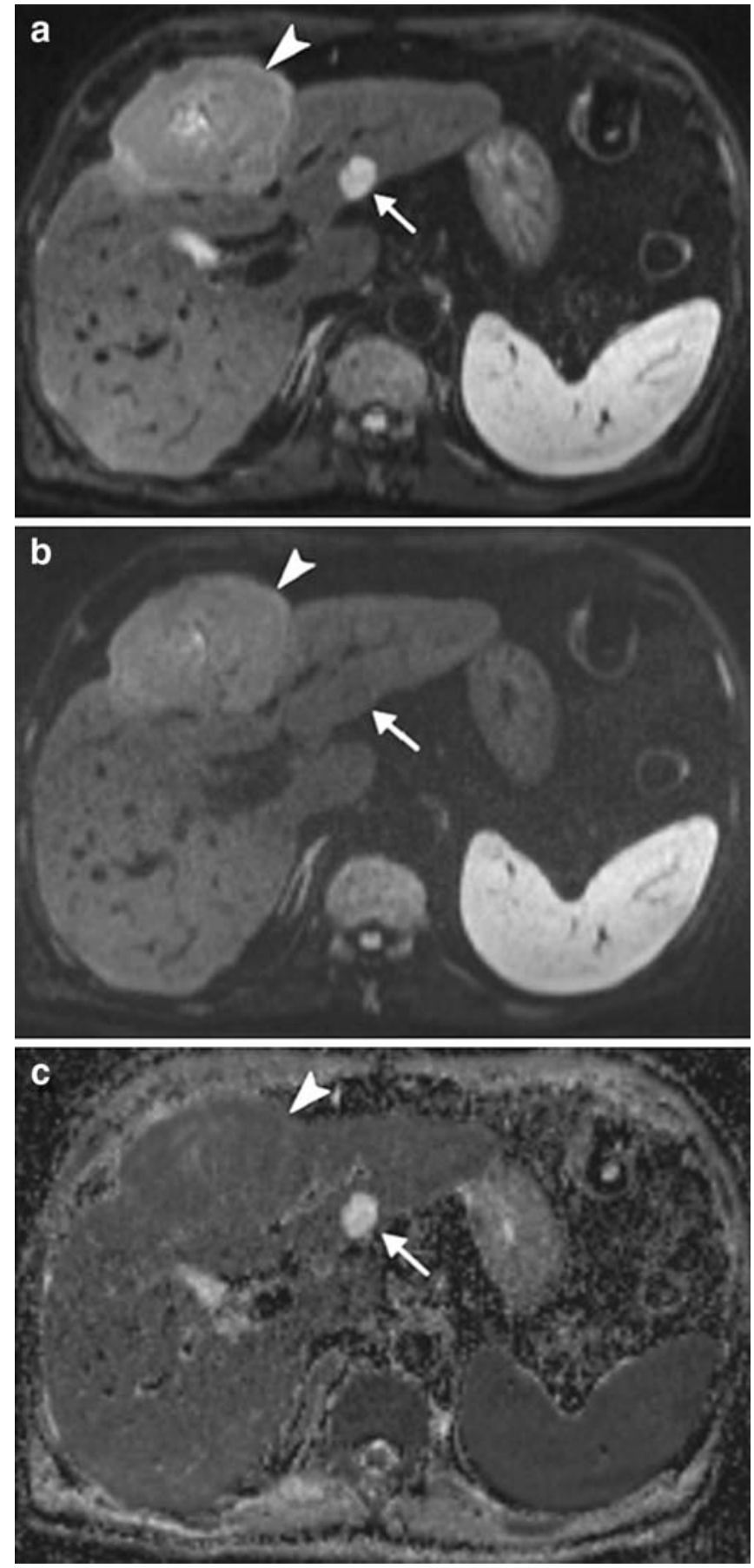

Fig. 3 DW-SS-EPI images for $b=50 \mathrm{~s} / \mathrm{mm}^{2}$ (a) and $b=600 \mathrm{~s} / \mathrm{mm}^{2}$ (b). c ADC map. The hepatocellular carcinoma in segment IV (arrowhead) shows a merely moderate signal loss from the $b=50 \mathrm{~s} / \mathrm{mm}^{2}$ to the $b=600 \mathrm{~s} / \mathrm{mm}^{2}$ DW-SS-EPI image. The cyst in segment II (arrow) displays markedly high signal intensity on the $b=50 \mathrm{~s} / \mathrm{mm}^{2} \mathrm{DW}-\mathrm{SS}-\mathrm{EPI}$ image and becomes isointense on the $b=600 \mathrm{~s} / \mathrm{mm}^{2}$ DW-SS-EPI image. On the corresponding ADC map, the tumour shows a low ADC value $\left(1.18 \times 10^{-3} \mathrm{~mm}^{2} / \mathrm{s}\right)$, whereas the cyst has a high $A D C$ value $\left(3.09 \times 10^{-3} \mathrm{~mm}^{2} / \mathrm{s}\right)$ (reproduced with permission from Bruegel et al. [33]) the lower end of the range, an effect attributed to perfusioninduced $\mathrm{ADC}$ increases in the normal liver measured at $b<$ $400 \mathrm{~s} / \mathrm{mm}^{2}$ in particular [35]. The ADC of segment II, anterior region, exceeds those measured in three other liver segments and is less reproducible, probably because of the increased exposure of segment II to cardiac motion artefacts and the use of respiratory triggering [33]. Kwee at al. recently reported that ADC measurements in respiratorytriggered DWI are significantly higher and less reproducible than in breath-hold and free-breathing DWI [36]. Another application of DWI is its use for control of treatment. Different authors demonstrated a significant increase in ADC from before to shortly after transcatheter arterial chemoembolisation in large groups of patients with hepatocellular carcinoma $[37,38]$, indicating that DWI could be used as a predictor of the effectivity of treatment. The location in liver can be a factor affecting the outcome of DWI, although a recent study revealed that the ADC values measured in segments V-VIII, right lobe, of the liver parenchyma of patients with benign focal lesions, malignant focal lesions and in patients without any lesions are very similar [39]. The ADC values measured in fasted livers tend to be lower than those in fed livers, probably because the portal vein bulk increases significantly in all cases [40]. Fasting could thus be of help in the discrimination of hepatic metastases (ADC slightly elevated) from liver parenchyma.

\section{Viscoelasticity}

Morphological criteria such as size, contour and shape are used in the diagnosis of diffuse liver disease. Changes in these measures occur late in the course of the disease, usually at an irreversible stage. Alterations in stiffness can be assessed by manual palpation, and more objectively by ultrasound (since 1990) [41] or MR elastography (MRE) (since 1995) [42, 43]. In MRE, the tissue's constitutive parameters are visualised by using motion encoding for imaging harmonic shear waves propagating in organs [42]. Shear waves are magnetically encoded by bipolar gradients that usually oscillate with the same frequency as the mechanical vibration. Liver fibrosis can be detected by making wave images of a single frequency from which the elastic and viscous moduli can be calculated [44-47]. In conventional MRE experiments the wave propagation speed and the wave-damping coefficient can be deduced by repeatedly applying variable driving frequencies. In a very simple model assuming that the medium is nonviscous, the shear modulus or stiffness $(\mu)$ of the tissue examined can be defined as:

$\mu=(f \lambda)^{2} \rho$

The wavelength $\lambda$ (in metres) visible on each phase difference image is used to calculate $\mu$, where $f$ is the driving frequency (in $\mathrm{Hz}$ ) and $\rho$ is the mass density in kilograms per 
cubic metre [44]. The frequency resolution of MRE data gained can be entered into various models to obtain two, three, or four independent constitutive parameters [48]. The relatively simple Voight model has been used in the characterisation of liver fibrosis because it fits the viscoelastic parameters of soft materials well [49]. Here, the stressstrain relationship is:

$\sigma=\left(\mu-\zeta \delta_{t}\right) \varepsilon$

with $\sigma$ the strain, $\varepsilon$ the stress, $\mu$ the shear modulus, $\zeta$ the shear viscosity (attenuation within the medium) and $\delta_{t}$ the timederivative operator. For a homogeneous isotropic viscoelastic medium, the complex modulus can then be related to elasticity $(\mu)$ and viscosity $(\eta)$ using:

$G_{M}(\omega)=\mu+i \omega \eta$

This results in six equations, three for the imaginary part and three for the real part, to estimate the two unknown viscoelastic parameters $\mu$ and $\eta[48,49]$.

A novel fast approach in MRE is to use broadband frequency encoding to acquire superposed tissue oscillations at multiple frequencies rather than one frequency at a time $[48,50]$. This method is based on the increases in wave propagation speed and the damping of shear waves in soft tissue with the harmonic driving frequency as a result of the dispersion (i.e. frequency dependence) of elastic waves in viscous media.

Several studies, both single frequency MRE [44] and multifrequency MRE [51], have shown that in high-grade liver fibrosis viscosity and/or elastic moduli are significantly elevated compared with the results in healthy volunteers. In a recent large study of 96 patients suspected of having chronic liver disease the elasticity was found to be significantly elevated at histopathology METAVIR scores for fibrosis higher than F1 [52]. Optimal cutoff values of elasticity were $2.5,3.1$ and $4.3 \mathrm{kPa}$ for fibrosis scores greater than F1, F2 and F3, respectively [52]. Systematic liver stiffness increases with increased fibrosis stage of chronic liver disease were also shown by others who examined 50 patients and concluded that the predicted sensitivity and specificity for detecting all grades of liver fibrosis was $98-99 \%$ [53]. In a third study (of 44 patients) MRE of liver tumours revealed significantly greater mean shear stiffness in malignant tumours $(10.1 \mathrm{kPa})$ compared with fibrotic liver $(5.9 \mathrm{kPa})$, benign tumours $(2.7 \mathrm{kPa})$ and normal liver $(2.3 \mathrm{kPa})$ [54]. This is illustrated by Fig. 4. A cutoff value of $5 \mathrm{kPa}$ differentiated benign tumours from malignant liver tumours. The masses examined ranged from 1.4 to $11 \mathrm{~cm}$ in diameter, but increasing tumour size, a factor expected to lead to decreases in stiffness as necrosis-associated water and fat contents increase, was not taken into account in this preliminary study [54]. It is concluded that MRE appears to be well suited to the noninvasive differentiation of fibrotic liver and malignant liver tumours from normal liver and benign lesions. According to a recent comprehensive review comparing different imaging modalities in the diagnosis of hepatic fibrosis and cirrhosis, to date only MRE has been able to stage fibrosis or diagnose mild disease while ultrasonic elastography and DWI appear next most promising [55].
Fig. 4 Patient with hepatic adenoma. a T2-weighted MR image shows hyperintense $8-\mathrm{cm}$ adenoma (arrow) in the right lobe of the liver. b Gadoliniumenhanced 3D spoiled gradientrecalled echo MR image shows intense arterial phase enhancement (arrow). Washout was evident in the portal venous phase (not shown). c Axial MR elastographic wave image shows good illumination of the tumour (circle). Waves in the tumour have a slightly longer length than those in the surrounding normal liver parenchyma. d Elastogram with a region of interest corresponding to the tumour shows a shear stiffness value of the tumour of $3.1 \mathrm{kPa}$ and of the surrounding liver of $2.4 \mathrm{kPa}$ (reproduced with permission from Venkatesh et al. [54])
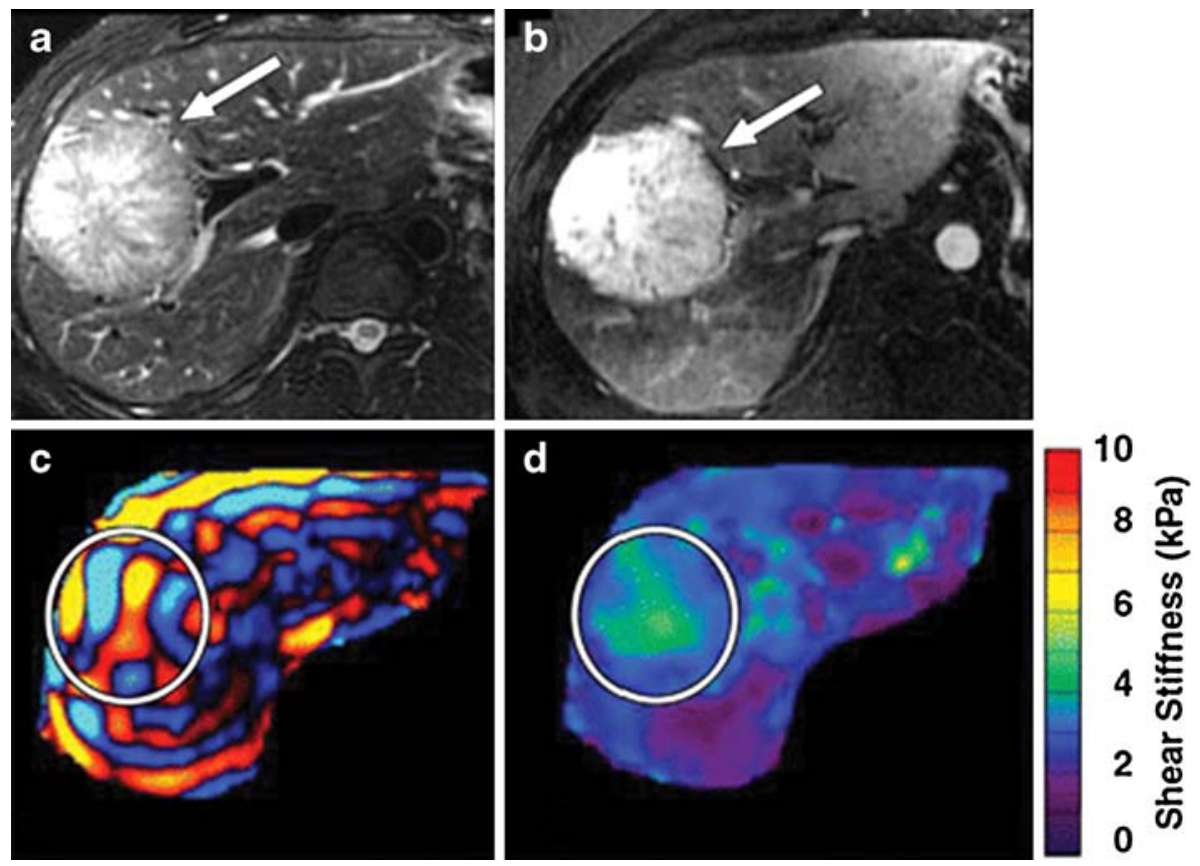


\section{Fat content}

Steatosis, the accumulation of fat in the liver, can lead to fatty liver disease (steatohepatitis and cirrhosis) [56, 57]. The prevalence of steatosis (liver fat greater than 5\% [58]) ranges from 30 to 34\% [59-62] and is an early marker of cardiovascular disease [62]. Liver fat contents under $20 \%$ are required for donor livers [63]. Among current MRI methods for quantifying liver fat content [64], single-voxel MR spectroscopy (MRS) has become the gold standard owing to the demonstration of high correlations with pathological analysis of liver samples [65, 66]. Localized MRS is based on spin-echo sequences and must therefore be corrected for the T2 relaxation of the water and fat signals (which may vary amongst different tissues), and also for T1 relaxation if a short TR is used. Even properly performed single-voxel MRS yields information about one volume only, rendering the method nearly as irreproducible as analysis of biopsies. Recently, we adapted multivoxel MRS for the determination of reproducible hepatic fat contents in volunteers and patients [67, 68]. This possibility of determining the water-to-fat contents for an array of voxels, yielding the average liver fat content with the standard deviation being a measure of heterogeneity, is illustrated by Fig. 5. Although MRS measurements of liver fat content are performed without suppression of the water signal, an additional water-suppressed measurement can be used to assess the composition of the fatty acid chains by focusing on the minor signals of the methene, diallylic, methylene to carboxyl, and allylic groups [69]. This can lead to improved understanding and management of fatty liver disorders.

MRI methods for quantification of liver fat content are faster, though, and therefore recommendable for use in clinical practice. Those in most widespread use are based on Dixon's two-point technique [70], for instance, a breathhold gradient echo dual flip angle adaptation to generate intermediate-weighted and T1-weighted opposed-phase and in-phase images from which tissue fat contents can be calculated [71]. Even after taking precautions to prevent occasional mix-ups of water and fat signals, the MRI fat determinations tend to overestimate liver fat content by up to $4 \%$, especially at the lower end of the range encountered in most healthy individuals (fat content less than 10\%) [68]. The correlation between MRI and MRS data is strong, however, so the systematic error in MRI measurements can be corrected for [68]. Others have proposed variations in the Dixon method using either three or more acquisitions rather than two. In one of these studies, using seven echoes, excellent correspondence was found between liver fat contents according to MRI and MRS [72]; however, as pointed out elsewhere [73], at the TR of $2,500 \mathrm{~ms}$ - the only one used - the spectral water signals were saturated relative to the fat $\left(T 1_{\text {water }} \gg T 1_{\text {fat }}\right)$. The resulting uncorrected systematic overestimation of liver fat in the MRS data implies that the closely matched MRI fat contents reported
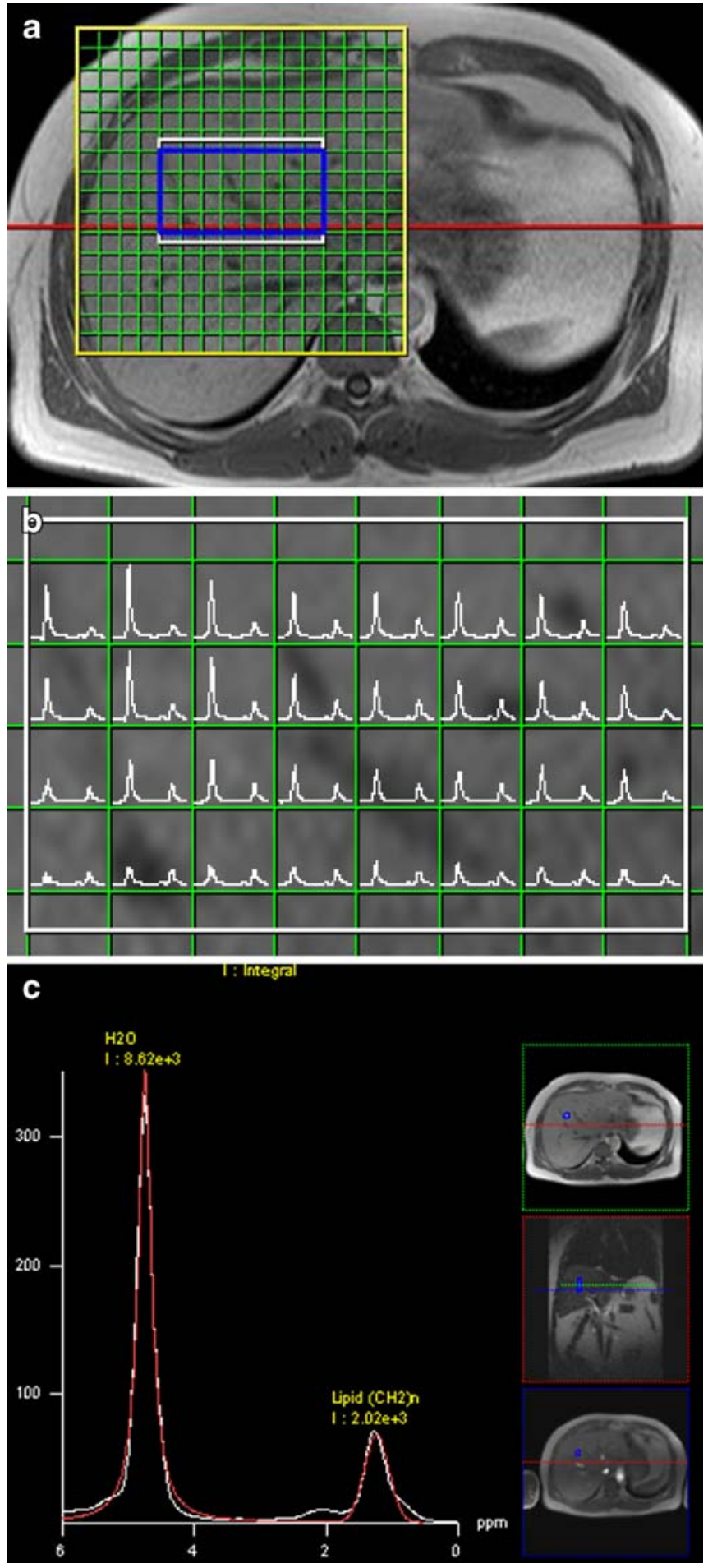

Fig. 5 The volume of interest (a), spectral map (b) and a curve fitted spectrum (c) of a healthy (obese) volunteer. The water and fat peaks in the 32 quantified voxels yield a liver fat content, i.e. the ratio of fat/(water + fat), of $21.3 \pm 5.5 \%$. Unlike single-voxel MRS giving a single value, multivoxel MRS provides a mean with a standard deviation, the latter being a measure of tissue heterogeneity (unpublished material from a study by Irwan et al. [68]) 
by O'Regan are also overestimated, especially at the lower end of the range where the MRI contents already exceeded the MRS fat contents by $0.2-1.1 \%$. Another recent modification is the sampling of the water and fat signals at in-phase and partially opposed-phase acquisition, meaning that the second image is acquired at a sampling angle not equal to $180^{\circ}$ [74]. Similar to the quadrature sampling method [75-77] and direct phase encoding [78], water and fat are separated as well as identified using the lagging phase relationship [74].

An alternative MRI method that is possibly more precise (with only small systematic error), is the slice-selective gradient echo technique with spectral-spatial excitation $[79,80]$. In fat-selective MRI the fat contents are typically calculated directly, i.e. after the appropriate corrections, from a water-saturated single slab fat image in which the signal intensities of liver tissue and subcutaneous fat are compared. In phantom measurements the fat contents were shown to be highly reproducible and well correlated with the results of optical image analysis [79]. On the other hand, because of the signal-to-noise ratio of the images, the detection threshold in vivo was assessed to be as high as $2 \%$ of volume [80]. All of the above MRI methods will work if $\mathrm{T} 1$ and $\mathrm{T} 2 *$ relaxation are corrected for, but will become less reproducible in the case of very short $\mathrm{T} 2 *$ due to, for example, iron overload. Overall, it appears that the Dixon-based MRI techniques for determining liver fat content currently are more reliable and robust than other methods, and thus recommended for routine clinical application.

\section{Metabolism (MR spectroscopy)}

In MRS nuclei other than hydrogen, such as phosphorus $\left({ }^{31} \mathrm{P}\right)$ and carbon $\left({ }^{13} \mathrm{C}\right)$, are hampered by sensitivity $\left({ }^{31} \mathrm{P}\right.$, $\left.{ }^{13} \mathrm{C}\right)$ and natural abundance $\left({ }^{13} \mathrm{C}\right)[81]$. Hydrogen $\left({ }^{1} \mathrm{H}\right.$, proton) has the highest sensitivity of all radiofrequency excitable nuclei and is therefore most suited to be studied in MRS, especially on low-field MRI systems. However, ${ }^{1} \mathrm{H}$ MRS detection of tissue metabolites such as cholinecontaining compounds (Cho) and creatine/phosphocreatine $(\mathrm{Cr})$ at concentrations near $1 \mathrm{mM}$ requires effective suppression of the abundant water and fat signals. For that reason, phosphorus $\left({ }^{31} \mathrm{P}\right) \mathrm{MRS}$ detection of phosphate metabolites (phosphomonoesters, PME; inorganic phosphate, $\mathrm{P}_{\mathrm{i}}$; phosphodiesters, PDE; phosphocreatine, PCr; and adenosine triphosphate, ATP, including the signals of its analogues UTP, GTP and CTP), has been performed in most human liver studies published to date. It should be noted here that because of their extremely small T2 relaxation times large molecules, such as those present in membranes, proteins, bone and DNA, do not contribute to clinical MR spectra. The acquisition and postprocessing methods, in particular how to quantify the peak areas of overlapping metabolite signals, are critical. This leads to discrepancies between studies, even in healthy controls [82-84]. For example, in clinical practice one has to compromise between the degree of $\mathrm{T} 1$ saturation as a result of large pulse angles and short repetition times (TR) on the one hand, and the signal-to-noise-ratio obtained on the other $[85,86]$. Even when high-field MRI equipment and/ or advanced techniques such as nuclear Overhauser effect enhancement and proton decoupling are used [87, 88], resulting in improved signal-to-noise ratios and better spectral resolution between peaks, the spatial resolution between adjacent MRS voxels should be to the order of a centimetre to allow for the detection of low-concentration metabolites.

Liver MRS studies focus on the status of the liver as a whole or on the characterisation of focal hepatic lesions. In the latter category of MRS studies one obviously wants to be able to measure MRS voxels smaller than the lesions of interest.

\section{Diffuse liver disease}

Phosphorus MRS Several large studies feature the use of ${ }^{31} \mathrm{P}$ MRS for studying the metabolic alterations in chronic liver disease, a disease caused by alcohol abuse, primary biliary cirrhosis, virus infections, primary sclerosing cholangitis etc. (Fig. 6). Cirrhotic patients have increased levels of PME [89, 90] and decreased PDE [91]. Correlations of the PME/PDE ratio with the results of liver biopsy [92] and with the degree of fibrosis [93] indicate that ${ }^{3 \mathrm{I}} \mathrm{P}$ MRS can be used for staging and grading of chronic liver disease. Decreases in PME/PDE were observed in response to antiviral treatment for hepatitis Crelated liver disease [94]. Recently, however, it was shown in a study of 80 cases of nonalcoholic fatty liver disease that the observed elevations of PME relative to healthy controls lost their significance when the results were corrected for body weight [95]. Furthermore, patients suffering from cachexia (body weight loss) as a result of cancer elsewhere in the body had increased liver PME levels and decreased ATP compared with weight-stable cancer patients and healthy controls [96, 97]. Thus, host body weight appears to be an underestimated factor with a significant impact on ${ }^{31} \mathrm{P}$ MR spectra of the liver, leading to the requirement of body-weight-matched control groups. ${ }^{31} \mathrm{P}$ magnetisation transfer quantification of the rate of ATP synthesis is developing into a new method of liver characterisation [98]. Another new ${ }^{31} \mathrm{P}$ MRS application is the diagnosis of rejection after liver transplantation. It was recently shown that chronic rejection $(n=18)$ can be differentiated from good graft function $(n=48)$ by the measurement of increased PME/ATP and $\mathrm{PDE} / \mathrm{ATP}$ ratios [99].

${ }^{1} \mathrm{H},{ }^{13} \mathrm{C}$ and ${ }^{19} \mathrm{~F}$ MRS Significant correlations between liver glutamine/glutamate and Cho signals and the stage of 


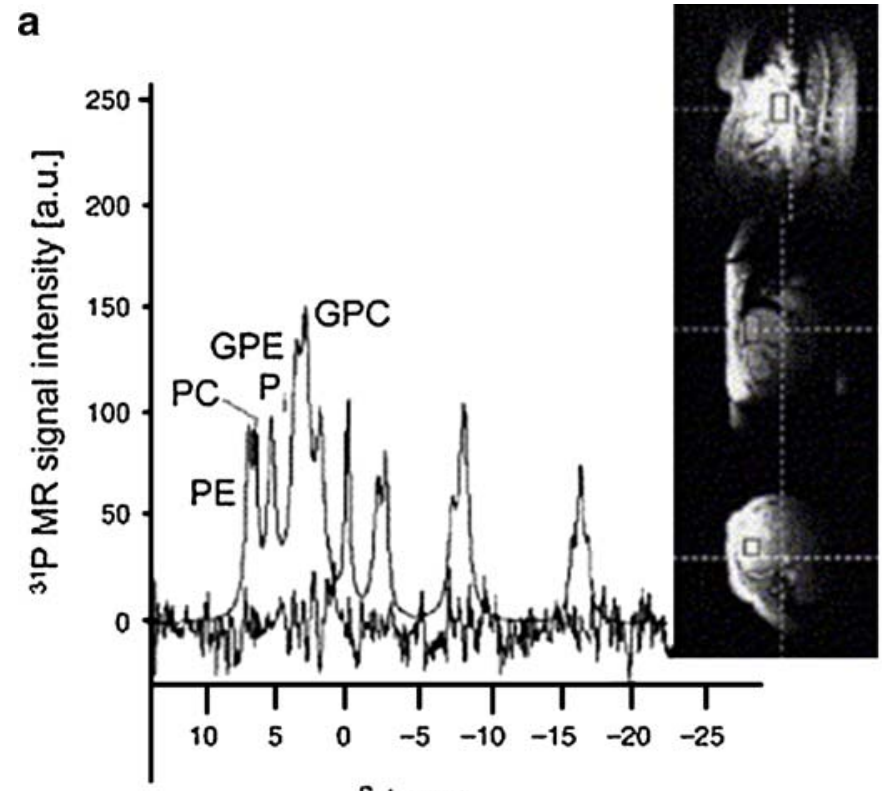

$\delta / \mathrm{ppm}$

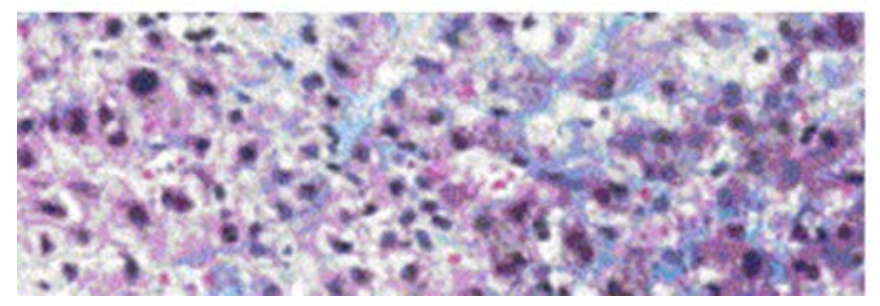

Fig. 6 a $\left\{{ }^{1} \mathrm{H}\right\}-{ }^{31} \mathrm{P}$ MRSI spectrum and corresponding hepatic histology of a woman with alcoholic liver fibrosis. The biopsy shows extensive periportal and parasinusoidal fibrosis in addition to typical ballooning of hepatocytes. b $\left\{{ }^{1} \mathrm{H}\right\}-{ }^{31} \mathrm{P}$ MRSI spectrum and corresponding hepatic histology of a man with cirrhosis of the liver. Biopsy shows micronodular alcoholic cirrhosis with typical

fibrosis in chronic hepatitis $\mathrm{C}$ patients [100] indicate that proton MRS, already a widespread method for quantifying liver fat content, will soon develop into a major line of metabolic liver research. Natural abundance (i.e. 1.1\%) carbon-13 $\left({ }^{13} \mathrm{C}\right)$ MRS demonstration of the presence of glycogen in the liver of a patient with glycogen storage disease suggests that MRS could replace liver biopsy in liver glycogen quantification [101]. Recently, others showed correlations between fasting plasma glucose level and both liver glycogen/glucose rate and liver glycogen peak/fasting rate in diabetic patients, indicating that ${ }^{13} \mathrm{C}$ MRS can be used for noninvasive measurement of glycogen storage/degradation ability in the liver and can thus assist in tailor-made therapy for diabetes [102]. Another special feature is the use of fluorine-19 $\left({ }^{19} \mathrm{~F}\right)$ MRS as a means of quantifying 5-fluorouracil and related metabolites in the liver and in focal disease under 5fluorouracil chemotherapy [103-106].

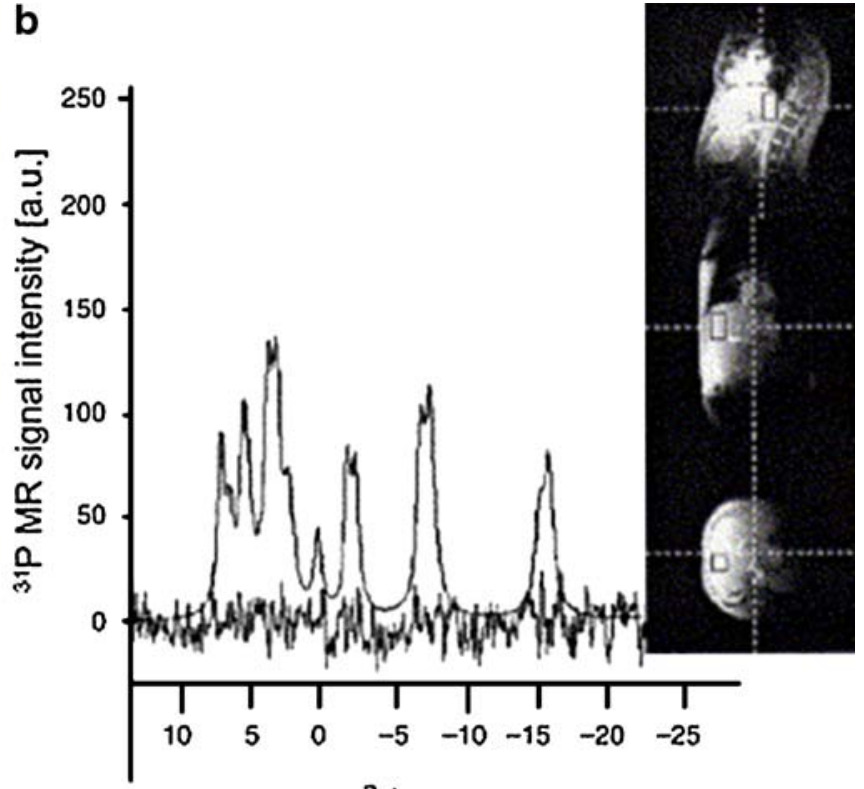

$\delta / \mathrm{ppm}$

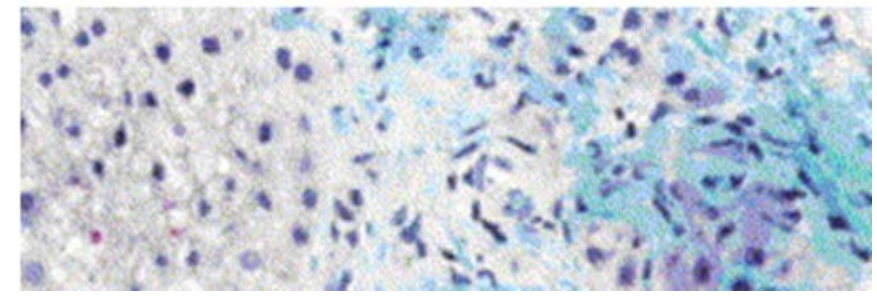

pseudolobules. Compared with spectra of healthy controls and the patient with noncirrhotic liver disease increased $\mathrm{PE} / \mathrm{PC}$ and, compared with hepatocellular carcinoma, increased GPE/GPC ratios can be observed. The position of the voxel observed is indicated in orthogonal slices (reproduced with permission from Schlemmer et al. [88])

\section{Liver function $\left({ }^{31} \mathrm{P}\right.$ MRS $)$}

Dynamic ${ }^{31} \mathrm{P}$ MRS showed PME (fructose-1-phosphate) increases and decreases in the levels of ATP and $P_{i}$ in healthy volunteers in response to bolus fructose administration, whereas in three adults with disorders of fructose metabolism no spectral changes were seen, providing proof of fructokinase dysfunction [107]. In response to fructose infusion, seven patients with nonalcoholic cirrhosis also showed reductions in the formation of PME and in the utilisation of $\mathrm{P}_{\mathrm{i}}$, thus providing metabolic evidence confirming the expected impairment of liver function [108]. Infusion of glucose, alanine and ATP caused modest alterations in the levels of liver metabolites in cancer patients with cachexia [109-111]. In normal liver, dietary fish oil supplementation was shown to result in PDE increases, indicating that lipid metabolism is influenced by dietary intake [112]. 


\section{Focal liver disease $\left({ }^{1} \mathrm{H}\right.$ MRS $)$}

The sensitivity and specificity of single-voxel ${ }^{1} \mathrm{H}$ MRS in diagnosing malignant hepatic tumours $(n=53)$ were reported to be less than $50 \%$ and $20 \%$, respectively [113], disappointing in view of ex vivo proton MRS results showing that normal liver and cirrhotic liver were distinguished from hepatocellular carcinoma (HCC) with accuracies of $100 \%$ and $98 \%$, respectively [114]. In patients re-examined shortly after transcatheter arterial chemoembolisation (TACE), reduced Cho and reduced Cho/lipid ratios were observed in HCC [37, 114]. It may be concluded that single-voxel MRS, while of use in tumour follow-up, is not sufficiently robust for tumour characterisation. One of the advantages in the use of multivoxel MRS [67, 68] in tumour heterogeneity studies is the possibility of retrospective positioning of the spectral map over the tumour. Considering normal liver fat contents of up to $5 \%$ [58], about two orders of magnitude higher than Cho in malignant tumours, optimal multivoxel MRS of liver tumours includes suppression of both lipid and water signals. Previous single-voxel MRS studies lacked lipid suppression [37, 113, 114]. In order to get direct comparisons of voxels containing tumour and normal liver tissue multivoxel MRS should be used, preferably with fat suppression in order to improve the detection of the millimolar range of metabolite signals (i.e. Cho in liver and elevated Cho in tumour) in liver tissues containing at least $0.3 \%$ fat, even in healthy subjects [68]. Thus, with incorporation of multivoxel MRS methods as well as lipid suppression methods, MRS should soon develop into a more successful method for the characterisation of liver tumours than has been reported to date. The increasing availability of high-field MR systems (3 T, $7 \mathrm{~T}$...) will enable future MRS studies to be performed faster and with enhanced spatial resolution, the latter in particular of interest in the study of small malignancies and tumour heterogeneity.

\section{Future prospects}

In perfusion MRI a promising new application is therapeutic monitoring of antiangiogenic drugs in liver tumours. The methods for quantifying liver iron content elevation, a measure of inflammation, liver disease and cancer, already appear to be optimised. It will be of interest to use the same methods for monitoring iron accumulations in other organs such as the heart. Because of the high perfusion fraction in liver, the apparent diffusion coefficients strongly depend on the gradient factors used in diffusion-weighted MRI. While complicating analysis, this offers the opportunity to study perfusion without contrast injection. Another novel method, MRE, has already been established as the only technique able to stage fibrosis or diagnose mild disease. Further studies are needed to validate the possible application of MRE in the diagnosis and monitoring of cancer. The MRS and MRI methods for determining liver fat content are already quite established and are expected to become a major instrument in epidemiological studies of populations increasingly suffering from overweight. Finally, the implementation of multivoxel methods is expected to greatly enhance the diagnostic value of MRS studies of focal liver disease, in particular at high-field strengths.

Open Access This article is distributed under the terms of the Creative Commons Attribution Noncommercial License which permits any noncommercial use, distribution, and reproduction in any medium, provided the original author(s) and source are credited.

\section{References}

1. Tian JL, Zhang JS (2006) Hepatic perfusion disorders: etiopathogenesis and related diseases. World $\mathrm{J}$ Gastroenterol 12:3265-3270

2. Lupescu IG, Grasu M, Capşa R, Pitrop A, Georgescu SA (2006) Hepatic perfusion disorders: computertomographic and magnetic resonance imaging. J Gastrointestin Liver Dis 15:273-279

3. Karabulut N, Elmas N (2006) Contrast agents used in MR imaging of the liver. Diagn Interv Radiol 12:22-30
4. Abdullah SS, Pialat JB, Wiart M, Duboeuf F, Mabrut J-Y, Bancel B, Rode A, Ducerf C, Baulieux J, Berthezene Y (2008) Characterization of hepatocellular carcinoma and colorectal liver metastasis by means of perfusion MRI. J Magn Reson Imaging 28:390-395

5. Miyazaki K, Collins DJ, Walker-Samuel S, Taylor JN, Padhani AR, Leach MO, Koh D-M (2008) Quantitative mapping of hepatic perfusion index using MR imaging: a potential reproducible tool for assessing tumour response to treatment with the antiangiogenic compound BIBF 1120, a potent triple angiokinase inhibitor. Eur Radiol 18:1414-1421
6. Hagiwara M, Rusinek H, Lee VS, Lasoda M, Bannan MA, Krinsky GA, Taouli B (2008) Advanced liver fibrosis: diagnosis with $3 \mathrm{D}$ whole-liver perfusion MR imaging - initial experience. Radiology 246:926-934

7. Inoue T, Kudo M, Hatanaka K, Takahashi S, Kitai S, Ueda T, Ishikawa E, Hagiwara S, Minami Y, Chung H, Ueshima K, Maekawa K (2008) Imaging of hepatocellular carcinoma: qualitative and quantitative analysis of postvascular phase contrast-enhanced untrasonography with Sonazoid. Oncology 75(suppl 1):48-54 
8. Finch CA, Bellotti V, Stray S, Lipschitz DA, Cook JD, Pippard MJ, Huebers HA (1986) Plasma ferritin concentration as a diagnostic tool. Clinical review. West J Med 145:657-663

9. Lipschitz DA, Cook JD, Finch CA (1974) A clinical evaluation of serum ferritin as an index of iron stores. N Engl J Med 290:1213-1216

10. Matzner Y, Konijn AM, Hershko C (1980) Serum ferritin in hematologic malignancies. Am J Hematol 9:13-22

11. Lee MH, Means RT Jr (1995) Extremely elevated serum ferritin levels in a university hospital: associated diseases and clinical significance. Am J Med 98:566-571

12. Drakoniaki E, Papakonstantinou O, Maris T, Vasiliadou A, Papadakis A, Gourtsoyiannis N (2005) Adrenal glands in beta-thalamassic major: magnetic resonance (MR) imaging features and correlation with iron stores. Eur Radiol 15:2462-2468

13. Kreeftenberg HG Jr., Mooyaart EL, Huizenga JR, Sluiter WJ (2000) Quantification of liver iron concentration with magnetic resonance imaging by combining T1-, T2- weighted spin echo sequences and a gradient echo sequence. Neth J Med 56:133-137

14. St Pierre TG (2005) Noninvasive measurement and imaging of liver iron concentrations using proton magnetic resonance. Blood 105:855-8618

15. Argyropoulou MI, Bonkovsky HL (1999) Hepatic iron concentration: noninvasive estimation by means of MR imaging techniques. Radiology 212:227-234

16. Bonkovsky HL (1999) Hepatic iron concentration: noninvasive estimation by means of MR imaging techniques. Radiology 212:227-234

17. Gandon Y, Olivié D, Guyader D, Aubé C, Oberta F, Sebille V, Deugnier Y (2004) Non-invasive assessment of hepatic iron stores by MRI. Lancet 363:357-362

18. Olthof A, Sijens P, Kreeftenberg H, Kappert P, Irwan R, van der Jagt E, Oudkerk M (2007) Correlation between serum ferritin levels and liver iron concentration determined by MR imaging: impact of hematologic disease and inflammation. Magn Reson Imaging 25:228-231
19. Perifanis V, Christoforidis A, Vlachaki E, Tsatra I, Spanos G, AthanassiouMetaxa M (2007) Comparison of effects of different long-term iron chelation regimens on myocardial and hepatic iron concentrations assessed with $\mathrm{T} 2 *$ magnetic resonance imaging in patients with beta-thalassemia major. Int J Hematol 86:385-389

20. Lam WWM, Au WY, Chu WCW, Tam S, Ha SY, Pennel DJ (2008) One-stop measurement of iron deposition in the anterior pituitary, liver, and heart in thalassemia patients. J Magn Reson Imaging 28:29-33

21. Alustiza JM, Artetxe J, Castiella A, Agirre C, Emparanza JI, Otazua P, Garcia- Bengoechea M, Barrio J, Mujica F, Recondo JA (2004) MR quantification of hepatic iron concentration. Radiology 230:479-484

22. Laine F, Reymann JM, Morel F, Langouet S, Perrin M, Guillygomarc'h A, Brissot P, Turmel V, Mouchel C, Pape D, Bellissant E, Deugnier Y (2006) Effects of phlebotomy therapy on cytochrome P450 2e1 activity and oxidative stress markers in dysmetabolic iron overload syndrome: a randomized trial. Aliment Pharmacol Ther 24:1207-1213

23. Papakonstantinou O, Maris TG, Kostaridou S, Ladis V, Vasiliadou A, Gourtsoyiannis NC (2005) Abdominal lymphadenopathy in beta-thalassemia: MRI features and correlation with liver iron overload and posttransfusion chronic hepatitis C. AJR Am J Roentgenol 185:219-224

24. Olthof AW, Sijens PE, Kreeftenberg HG, Kappert P, van der Jagt E, Oudkerk M (2008) Non-invasive liver iron concentration measurement by MRI: Comparison of two validated protocols. Eur J Radiol. doi:10.1016/j. ejrad.2008.02.008

25. Le Bihan D, Breton E, Lallemand D, Aubin ML, Vignaud J, Laval-Jeantet M (1988) Separation of diffusion and perfusion in intravoxel incoherent motion MR imaging. Radiology 168:497-505

26. Thoeny HC, De Keyzer F, Boesch C, Hermans R (2004) Diffusion-weighted imaging of the parotid gland: influence of the choice of b-values on the apparent diffusion coefficient value. J Magn Reson Imaging 20:786-790

27. Yeung DKW, Wong SYS, Griffith JF, Lau EMC (2004) Bone marrow diffusion in osteoporosis: evaluation with quantitative MR diffusion imaging. J Magn Reson Imaging 19:222-228

28. Luciani A, Vignaud A, Cavet M, Van Nhieu JT, Mallat A, Ruel L, Laurent A, Deux JF, Brugieres P, Rahmouni A (2008) Liver cirrhosis:intravoxel incoherent motion MR imaging. Radiology 249:891-899
29. Goshima S, Kanematsu M, Kondo H, Yokoyama R, Kajita K, Tsuge Y, Watanabe H, Shiratori Y, Onezuka M, Moriyama N (2008) Diffusionweighted imaging of the liver: optimizing $b$ value for the detection and characterization of benign and malignant hepatic lesions. J Magn Reson Imaging 28:691-697

30. Yamada I, Aung W, Himeno Y, Nakagawa T, Shibuya H (1999) Diffusion coefficients in abdominal organs and hepatic lesions: evaluation with intravoxel incoherent motion echo-planar MR imaging. Radiology 219:617623

31. Koh DM, Scurr E, Collins DJ, Pirgon A, Kanber B, Karanjia N, Brown G, Leach MO, Husband JE (2006) Colorectal hepatic metastases: quantitative measurements using single-shot echoplanar diffusion-weighted MR imaging. Eur Radiol 16:1898-1905

32. Sun XJ, Quan XY, Huang FH, Xu YK (2005) Quantitative evaluation of diffusion-weighted magnetic resonance imaging of focal hepatic lesions. World J Gastroenterol 11:6535-6537

33. Bruegel M, Holzapfel K, Gaa J, Woertler K, Waldt S, Kiefer B, Stemmer A, Ganter C, Rummeny EJ (2008) Characterization of focal liver lesions by ADC measurements using a respiratory triggered diffusionweighted single-shot echo-planar MR imaging technique. Eur Radiol 18:477-485

34. Inan N, Arslan A, Akansel G, Anik Y, Sarisoy TH, Ciftci E, Dimerci A (2007) Diffusion-weighted imaging in the differential diagnosis of simple and hydatid cysts of the liver. AJR Am J Roentgenol 189:1031-1036

35. Girometti R, Furlan A, Esposito G, Bazzocchi M, Como G, Soldano F, Isola M, Toniutto P, Zuiani C (2008) Relevance of $b$-values in evaluating liver fibrosis: a study in healthy and cirrhotic subjects using two single-shot spin-echo echo-planar diffusionweighted sequences. J Magn Reson Imaging 28:411-419

36. Kwee TC, Takahara T, Koh DM, Nievelstein RA, Kuijten PR (2008) Comparison and reproducibility of ADC measurements in breathhold, respiratory triggered, and free breathing diffusion-weighted MR imaging of the liver. J Magn Reson Imaging 28:1141-1148 
37. Chen YC, Li CW, Kuo YT, Jaw TS, Wu DK, Jao JC, Hsu JS, Liu GC (2006) Early response of hepatocellular carcinoma to transcatheter arterial chemoembolisation: choline levels and MR diffusion constants - initial experience. Radiology 239:448-456

38. Kamel IR, Liapi E, Reyes DK, Zuhurak M, Bleumke DA, Geschwind JFH (2009) Unresectable hepatocellular carcinoma: serial early vascular and cellular changes after transarterial chemoembolization as detected with MR imaging. Radiology 250:466-473

39. Gourtsoyianni S, Papanicolaou N, Yarmenitis S, Maris T, Karantanas A, Gourtsoyiannis N (2008) Respiratory gated diffusion weighted imaging of the liver: value of apparent diffusion coefficient measurements in the differentiation between most commonly encountered benign and malignant focal liver lesions. Eur Radiol 18:486-492

40. Hoolingsworth KG, Lomas DJ (2006) Influence of perfusion on hepatic MR diffusion measurement. NMR Biomed 19:231-235

41. Parker KJ, Huang SR, Musulin RA, Lerner RM (1990) Tissue response to mechanical vibration $\mathrm{s}$ for sonoelasticity imaging. Ultrasound Med Biol 16:241-246

42. Muthupillai R, Lomas DJ, Rossman PJ, Greenleaf JF, Manduca A, Ehman RL (1995) Magnetic resonance elastography by direct visualization of propagating acoustic strain waves. Science 269:1854-1857

43. Plewes DB, Betty I, Urchuk SN, Soutar I (1995) Visualizing tissue compliance with MR imaging. J Magn Reson imaging 5:733-738

44. Rouvière $\mathrm{O}$, Yin $\mathrm{M}$, Dresner MA, Rossman PJ, Burgart LJ, Fidler JL, Ehman RL (2006) MR elasticity of the liver: preliminary results. Radiology 240:440-448

45. Huwart L, Peeters F, Sinkus R, Annet L, Salameh N, ter Beek LC, Horsmans Y, Van Beers BE (2006) Liver fibrosis: non-invasive assessment with MR elastography. NMR Biomed 19:173179

46. Klatt D, Asbach P, Rump J, Papazoglou S, Somasundaram M, Modrow J, Braun J, Sack I (2006) In vivo determination of hepatic stiffness using steady-state free precession magnetic resonance elastography. Invest Radiol 41:841-848
47. Yin M, Woollard J, Wang X, Torres VE, Harris PC, Ward CJ, Glaser KJ, Manduca A, Ehman RL (2007) Quantitative assessment of hepatic fibrosis in an animal model with magnetic resonance elastography. Magn Reson Med 58:346-353

48. Klatt D, Hamhaber U, Asbach P, Braun J, Sack I (2007) Noninvasive assessment of the rheological behavior of human organs using multifrequency MR elastography: a study of brain and liver viscoelasticity. Phys Med Biol 52:7281-7294

49. Salameh N, Peeters F, Sinkus R, Abarca-Quinones J, Annet L, ter Beek LC, Leclercq I, Van Beers BE (2007) Hepatic viscoelastic parameters measured with MR elastography: correlations with quantitative analysis of liver fibrosis in the rat. J Magn Reson Imaging 26:956-962

50. Rump J, Klatt D, Braun J, Warmuth C, Sack I (2007) Fractional encoding of harmonic motions in MR elastography. Magn Reson Med 57:388-395

51. Asbach P, Klatt D, Hamhaber U, Braun J, Somasundaram R, Hamm B, Sack I (2008) Assessment of liver viscoelasticity using multifrequency MR elastography. Magn Reson Med 60:373-379

52. Huwart L, Sempoux C, Salameh N, Jamart J, Annet L, Sinkus R, Peeters F, ter Beek LC, Horsmans Y, Van Beers BE (2007) Liver fibrosis: non-invasive assessment with MR elastography versus aspartate aminotransferase-to-platelet ratio index. Radiology 245:458-466

53. Yin M, Talwalkar JA, Glaser KJ, Manduca A, Grimm RC, Rossman PJ, Fidler JL, Ehman RL (2007) A preliminary assessment of hepatic fibrosis with magnetic resonance elastography. Clin Gastroenterol Hepatol 5:12071213

54. Venkatesh SK, Yin M, Glockner JF, Takahashi N, Araoz PA, Talwalkar JA, Ehman RL (2008) MR elastography of liver tumors: preliminary results. Am J Roentgenol AJR 190:1534-1540

55. Bonekamp S, Kamel I, Solga S, Clark J (2009) Can imaging modalities diagnose and stage hepatic fibrosis and cirrhosis accurately? J Hepatology 50:17-35

56. Adams LA, Sanderson S, Lindor KD, Angulo P (2005) The histological course of nonalcoholic fatty liver disease: a longitudinal study of 103 patients with sequential liver biopsies. J Hepatol 42:132-138

57. Dam-Larsen S, Franzmann MB, Christoffersen P, Larsen K, Becker U, Bendtsen F (2005) Histological characteristics and prognosis in patients with fatty liver. Scand J Gastroenterol $40: 460-467$
58. Hoyumpa AM Jr, Green HL, Dunn GD, Schenker S (1975) Fatty liver: biochemical and clinical considerations. Am J Dig Dis 20:1142-1170

59. Volzke H, Robinson DM, Kleine V, Deutcher R, Hoffmann W, Ludeman W, Schminke U, Kessler C, John U (2005) Hepatic steatosis is associated with an increased risk of carotid atherosclerosis. World J Gastroenterol 11:18481853

60. Browning JD, Szczepaniak LS, Dobbins R, Nuremberg P, Horton JD, Cohen JC, Grundy SM, Hobbs HH (2004) Prevalence of hepatic steatosis in an urban population in the United States: impact of ethnicity. Hepatology 40:1387-1395

61. Szczepaniak LS, Nurenberg P, Leonard D, browning JD, Reingold JS, Grundy S, Hobbs HH, Dobbins RL (2005) Magnetic resonance spectroscopy to measure hepatic triglyceride content: prevalence of hepatic steatosis in the general population. Am J Physiol Endocrinol Metab 288:E462-E468

62. Targher G, Bertolini L, Padovani R, Rodella S, Tessari R, Zenari L, Day C, Arcaro G (2004) Relation of nonalcoholic hepatic steatosis to early carotid atherosclerosis in healthy men: role of visceral fat accumulation. Diabetes Care 27:2498-2500

63. Kim SH, Lee JM, Han JK, Lee JY, Lee KH, Han CJ, Jo JY, Yi NJ, Suh KS, Shin KS, Jo SY, Choi BI (2006) Hepatic macrosteatosis: predicting appropriateness of liver donation by using MR imaging - correlation with histopathologic findings. Radiology 240:117-129

64. Valls C, Iannacconne R, Alba E, Murakami T, Hori M, Passariello R, Vilgrain V (2006) Fat in the liver: diagnosis and characterization. Eur Radiol 16:2292-2308

65. Longo R, Ricci C, Masutti F, Vidimari R, Crocé LS, Bercich L, Tiribelli C, Dalla Palma L (1993) Fatty infiltration of the liver. Quantification by ${ }^{1} \mathrm{H}$ localized magnetic resonance spectroscopy and comparison with computed tomography. Invest Radiol 4:297-302

66. Thomsen C, Becker U, Winkler K, Christoffersen P, Jensen M, Henriksen O (1994) Quantification of liver fat using magnetic resonance spectroscopy. Magn Reson Imaging 12:487-495 
67. Sijens PE, Smit GP, Borgdorff MAJ, Kappert P, Oudkerk M (2006) Multiple voxel ${ }^{1} \mathrm{H}$ MR spectroscopy of phosphorylase-b kinase deficient patients (GSD IXa) showing an accumulation of fat in the liver that resolves with aging. J Hepatol 45:851-855

68. Irwan R, Edens MA, Sijens PE (2008) Assessment of the variations in fat content in normal liver using a fast quantification MR imaging method in comparison with results obtained by spectroscopic imaging. Eur Radiol 18:806-813

69. Johnson NA, Walton DW, Sachinwalla T, Thompson CH, Smith K, Ruell PA, Stannard SR, George J (2008) Noninvasive assessment of hepatic lipid composition: advancing understanding and management of fatty liver disorders. Hepatology 47:1513-1523

70. Dixon WT (1984) Simple proton spectroscopic imaging. Radiology 153:189194

71. Hussain HK, Chenevert TL, Londy FJ, Gulani V, Swanson SD, McKenna BJ, Appelman HD, Adusumilli S, Greenson JK, Conjeevaram HS (2005) Hepatic fat fraction: MR imaging for quantitative measurement and display - early experience. Radiology 237:1048-1055

72. O'Regan DP, Callaghan MF, Wylezinska-Arridge M, Fitzpatrick J, Naoumova RP, Hajnal JV, Schmitz SA (2008) Liver fat content and T2*: simultaneous measurement by using breath-hold multiecho MR imaging at $3.0 \mathrm{~T}$-feasibility. Radiology 247:550557

73. Guiu B, Loffroy R, Cercueil JP, Krause D (2008) Multiecho MR imaging and proton MR spectroscopy for liver fat quantification (letter-to-the-editor). Radiology 249:1081

74. Xiang QS (2006) Two-point water-fat imaging with partially opposed-phase (POP) acquisition: an asymmetric Dixon method. Magn Reson Med 56:572-584

75. Paltiel Z (1985) Separate water and lipids images obtained by a single scan. In: Proceedings of the 4th Annual Meeting of SMRM, New York, USA, pp 172-173

76. Patrick JL, Haacke EM, Hahn JE (1985) Water fat separation and chemical shift artefact correction using a single scan. In: Proceedings of the 4th Annual Meeting of SMRM, New York, USA, pp 174-175
77. Ahn CB, Lee SY, Nalcioglu O, Cho ZH (1986) Spectroscopic imaging by quadrature modulated echo time shifting. Magn Reson Imaging 4:110-111

78. Xiang QS, An L (1997) Water-fat imaging with direct phase encoding. J Magn Reson Imaging 7:1002-1015

79. Cottler SJ, Guzman G, Layden-Almer J, Mazzone T, Layden TJ, Zhou XJ (2007) Measurement of liver fat content using selective saturation at $3.0 \mathrm{~T}$. J Magn Reson Imaging 25:743-748

80. Machan J, Thamer C, Schnoedt B, Stefan N, Haring H-U, Claussen CD, Frische A, Schick F (2006) Hepatic lipid accumulation in healthy subjects: a comparative study using spectral fatselective MRI and volume-localized ${ }^{1} \mathrm{H}-\mathrm{MR}$ spectroscopy. Magn Reson Med 55:913-917

81. Sijens PE, Oudkerk M (2005) Clinical magnetic resonance spectroscopy. Imaging Decis MRI 9:39-48

82. Sijens PE, Dagnelie PC, Halfwerk S, van Dijk P, Wicklow K, Oudkerk M (1998) Understanding the discrepancies between 31P MR spectroscopy assessed liver metabolite concentrations from different institutions. Magn Reson Imaging 16:205-211

83. Buchli R, Meier D, Martin E, Boesiger P (1994) Assessment of absolute metabolite concentrations in human tissue by ${ }^{31} \mathrm{P}$ MRS in vivo. Magn Reson Med $32: 453-458$

84. Norén B, Lundberg P, Ressner M, Wirell S, Almer S, Smedby O (2005) Absolute quantification of human liver metabolite concentrations by localized in vivo 31P NMR spectroscopy in diffuse liver disease. Eur Radiol 15:148-157

85. Cox IJ, Couts GA, Gadian DG, Ghosh P, Sargentoni J, Young IR (1991) Saturation effects in phosphorus-31 magnetic resonance spectra of the human liver. Magn Reson Med 17:5361

86. Sijens PE, van Dijk P, Dagnelie PC, Oudkerk M (1995) Non-T1 weighted 31P MR chemical shift imaging of the human liver. Magn Reson Imaging 13:621-628

87. Li CW, Negendank WG, MurphyBoesch J, Padavic-Shaller K, Brown TR (1996) Molar quantitation of hepatic metabolites in vivo proton-decoupled, nuclear Overhauser effect enhanced ${ }^{31} \mathrm{P}$ NMR spectra localized by three-dimensional chemical shift imaging. NMR Biomed 9:141-155

88. Schlemmer H-P, Sawatzki T, Sammet S, Dornacher I, Bachert P, van Kaick G, Waldherr R, Seitz HK (2005) Hepatic phospholipids in alcoholic liver disease assessed by proton-decoupled ${ }^{31} \mathrm{P}$ magnetic resonance spectroscopy. $\mathrm{J}$ Hepatol 42:752-759
89. Menon DK, Sargentoni J, TaylorRobinson SD, Bell JD, Cox IJ, Bryant DJ, Coutts GA, Rolles K, Burroughs AK, Morgan MY (1995) Effect of functional grade and etiology on in vivo hepatic phosphorus-31 magnetic resonance spectroscopy in cirrhosis: biochemical basis of spectral appearances. Hepatology 21:417-427

90. van Wassenaer-van Hall $\mathrm{HN}$, van der Grond J, van Hattum J, Kooijman C, Hoogenraad TU, Mali WP (1995) ${ }^{31} \mathrm{P}$ magnetic resonance spectroscopy of the liver: correlation with standardized serum, clinical, and histological changes in diffuse liver disease. Hepatology 21:443-449

91. Dezortova M, Taimr A, Skoch A, Spicak J, Hajek M (2005) Etiology and functional status of liver cirrhosis by ${ }^{31}$ P MR spectroscopy. World J Gastroenterol 11:6926-6931

92. Lim AKP, Patel N, Hamilton G, Mylvahan K, Kuo Y-T, Goldin RD, Taylor-Robinson SD (2007) 31P MR spectroscopy in assessment of response to antiviral therapy for hepatitis C virus-related liver disease. Am J Roentgenol AJR 189:819-823

93. Norén B, Dahlquist O, Lundberg P, Almer S, Kechagias S, Ekstedt M, Franzèn L, Wirell S, Smedby O (2008) Separation of advanced from mild cirrhosis in diffuse liver disease using 31P magnetic resonance spectroscopy. Eur Radiol 15:148-157

94. Lim AKP, Patel N, Hamilton G, Goldin RD, Hajnal JV, Taylor-Robinson SD (2003) Findings at 31P magnetic resonance spectroscopy correlate with histology in chronic hepatitis $\mathrm{C}$ virus infection. Hepatology 27:788-794

95. Sharma R, Sinha S, Danishad KA, Vikram NK, Gupta A, Ahuja V, Jagannathan NR, Pandey RM, Misra A (2009) Investigation of hepatic gluconeogenesis pathway in non-diabetic Asian Indians with non-alcoholic fatty liver disease using in vivo $\left({ }^{31} \mathrm{P}\right)$ phosphorus magnetic resonance spectroscopy. Atherosclerosis 203(1):291-297. doi: $10.1016 /$ j.atherosclero sis.2008.06.016

96. Dagnelie PC, Sijens PE, Kraus DJ, Planting AS, van Dijk P (1999) Abnormal liver metabolism in cancer patients detected by ${ }^{31} \mathrm{P}$ MR spectroscopy. NMR Biomed 12:535-544

97. Leij-Halfwerk S, Dagnelie PC, Kappert P, Oudkerk M, Sijens PE (2000) Decreased hepatic energy and phosphorylation status in the liver of advanced lung cancer patients with weight loss. J Hepatol 32:887-892 
98. Schmid AI, Chmelik M, Szendroedi J, Krššák M, Brehm A, Moser E, Roden M (2008) Quantitative ATP synthesis in human liver measured by localized ${ }^{31} \mathrm{P}$ spectroscopy using the magnetization transfer experiment. NMR Biomed 21:437-443

99. Jiang T, Liu S, Xiao XS, Toa XF, Liu GH, Wang JL (2008) Diagnosis of rejection after liver transplantation: use of phosphorus-31 magnetic resonance spectroscopy. Abdom Imaging. doi:10.1007/s00261-008-9451-1

100. Orlacchio A, Bolacchi F, Cadioli M, Bergamini A, Cozzolino V, Angelico M, Simonetti G (2008) Evaluation of the severity of chronic hepatitis $\mathrm{C}$ with 3-T ${ }^{1} \mathrm{H}-\mathrm{MR}$ spectroscopy. AJR Am J Roentgenol 190:1331-1339

101. Roser W, Beckmann N, Wiesman U, Seelig J (1996) Absolute concentration of the hepatic glycogen content in a patient with glycogen storage disease by ${ }^{13} \mathrm{C}$ magnetic resonance spectroscopy. Magn Reson Imaging 14:1217-1220

102. Tomiyasu M, Obata T, Nishi Y, Nakamoto H, Nonaka H, Takayama Y, Autio J, Ikehira H, Kanno I (2009) Monitoring of liver glycogen synthesis in diabetic patients using carbon-13 MR spectroscopy. Eur J Radiol. doi:10.1016/j.ejrad.2008.10.019

103. Wolf W, Albright MJ, Silver MS, Weber H, Reichart U, Sauer R (1987) Fluorine-19 NMR spectroscopic studies of the metabolism of patients undergoing chemotherapy. Magn Reson Imaging 5:165-169
104. Li CW, Negendank WG, Padavic-Shaller KA, O'Dwyer PJ, Murphy-Boesch J, Brown TR (1996) Quantitation of 5-fluorouracil catabolism in human liver in vivo by threedimensional localized ${ }^{19} \mathrm{~F}$ magnetic resonance spectroscopy. Clin Cancer Res 2:339-345

105. Semmler W, Bachert-Bauman P, Gückel F, Ermark F, Schlag P, Lorenz WJ, van Kaick G (1990) Real-time follow-up of 5-fluorouracil in the liver of tumor patients by means of F-19 MR spectroscopy. Radiology 174:141-145

106. van Laarhoven HWM, Klomp DWJ, Rijpkema M, Kamm YLM, Wegener DJT, Barentz JO, Punt CJA, Heerschap A (2007) Prediction of chemotherapeutic response of colorectal liver metastases with dynamic gadolinium-DTPA-enhanced MRI and localized ${ }^{19} \mathrm{~F}$ MRS pharmacokinetic studies of 5-fluorouracil. NMR Biomed 20:128-140

107. Boesiger P, Buchli R, Meier B, Steinmann B, Gitzelmann R (1994) Changes of liver metabolite concentrations in adults with disorders of fructose metabolism after intravenous fructose by ${ }^{31} \mathrm{P}$ magnetic resonance spectroscopy. Pediatr Res 36:436-440

108. Dufour JF, Stoupis C, Lazeyras F, Vock P, Terrier F, Reichen J (1992) Alterations in hepatic fructose metabolism in cirrhotic patients demonstrated by dynamic ${ }^{31}$ phosphorus spectroscopy. Hepatology 15:835-842

109. Leij-Halfwerk S, Dagnelie PC, van den Berg JWO Wilson JHP, Sijens PE (2000) Hepatic sugar phosphate levels and rate of gluconeogenesis in lung cancer: simultaneous turnover measurements and ${ }^{31} \mathrm{P}$ magnetic resonance spectroscopy in vivo. Clin Sci 98:167174
110. Leij-Halfwerk S, van den Berg JWO, Sijens PE, Wilson JHP, Oudkerk M, Dagnelie PC (2000) Altered hepatic gluconeogenesis during L-alanine infusion in weight losing lung cancer patients as observed by ${ }^{31} \mathrm{P}$ MR spectroscopy and turnover measurements. Cancer Res 60:618-623

111. Leij-Halfwerk S, Agteresch HJ, Sijens PE, Dagnelie PC (2002) Adenosine triphosphate infusion increases liver energy status in advanced lung cancer patients: an in vivo ${ }^{31} \mathrm{P}$ magnetic resonance spectroscopy study. Hepatology 35:421-424

112. Dagnelie PC, Bell JD, Cox IJ, Menon DK, Sargentoni J, Couts GA, Williams SCR (1993) Effects of fish oil on phospholipid metabolism in human and rat liver studied by ${ }^{31} \mathrm{P}$ NMR spectroscopy in vivo and in vitro. NMR Biomed 6:157-162

113. Kuo YT, Li CW, Chen CY, Jao J, Wu DK, Liu GC (2004) In vivo proton magnetic resonance spectroscopy of large focal hepatic lesions and metabolite change of hepatocellular carcinoma before and after transcatheter arterial chemoembolization using 3.0-T MR scanner. J Magn Reson Imaging 19:598-604

114. Soper R, Himmelreich U, Painter D, Somorjai RL, Lean CL, Dolenko B, Mountford CE, Russell P (2002) Pathology of hepatocellular carcinoma and its precursors using proton magnetic resonance spectroscopy and a statistical classification strategy. Pathology 34:417-422 